\title{
Use of Botanicals in Food Supplements
}

\author{
Regulatory Scope, Scientific Risk Assessment and Claim Substantiation
}

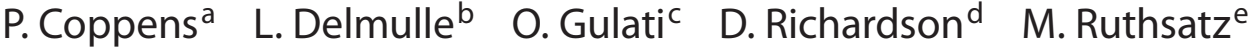 \\ H. Sievers ${ }^{f}$ S. Sidani ${ }^{9}$ \\ ${ }^{a}$ European Responsible Nutrition Alliance, Brussels, ${ }^{b}$ Ortis, Elsenborn, Belgium; ${ }^{c}$ Horphag Research \\ Management Ltd, Geneva, Switzerland; ${ }^{\mathrm{d} D P R}$ Nutrition Ltd., Croydon, UK; ${ }^{\mathrm{e}}$ Innéov, Asnières, France; \\ fPhytolab, Vestenbergsgreuth, Germany; ${ }^{9}$ Seven Seas, Hull, UK
}

\section{Key Words}

Botanicals, safety assessment $\cdot$ Herbal medicinal products,

legislation · Food supplements, health claims • Risk

assessment, herbal medicine $\cdot$ Functional foods, herbal experience and grading of evidence. Conclusions: A model for safety and efficacy assessment of botanical food supplements in the EU is proposed, and should be taken into consideration in the development of legislation and scientific research on botanicals.

Copyright $\odot 2006$ S. Karger AG, Basel

\begin{abstract}
Background/Aims: In the European Union, an elaborate legal framework regulates botanical products both under food and medicinal law. The decision as to which legal framework applies to an individual product may differ between the Member States. In the case of botanical food supplements, all food law provisions apply to their manufacturing, composition and marketing, including the new claims legislation. Methods: Elements from EU and national law, scientific and other publications are brought together to investigate how to clarify the differentiation between the use of botanicals for medicinal and health-promoting purposes on a scientific basis. Results: Guidance on the safety assessment and quality evaluation of botanicals is proposed in light of the different approaches described in the scientific literature with particular attention to the concept of longterm use as an integral part of safety evaluation. Guidance on claims substantiation is also included, taking into consideration the proposed legislation, the concept of long-term
\end{abstract}

This paper is the result of work commissioned by the European Botanical Forum and the conclusions of a workshop held in Brussels on November 30 to December 1, 2005.

\section{Introduction}

Botanical products in pre-dosed forms have been used for decades for their health-promoting and therapeutic properties. Many countries regulate the use of these products on their own territory, both as medicinal products and as food supplements [1].

The European Union has considered these products in several legislative texts ${ }^{1}$.

(1) Medicinal use has been harmonized through the Traditional Herbal Medicinal Product Directive (THMPD) [2].

(2) Food use is subject to the requirements of the General Food Law Regulation (GFLR) 178/2002 [3].

(3) The food use of botanicals is also covered in the Food Supplements Directive (FSD) 2002/46/EC [4]. This requires that, before 12 July 2007, the European Commis-

The legal text of the European Union are easily accessible through the EURLEX website: http://europa.eu.int/eur-lex/en/

P. Coppens

European Botanical Forum

Rue de l'Association, 50

$\mathrm{BE}-1000$ Brussels (Belgium)

Tel. +32 220911 50, Fax +32 222330 64, E-Mail info@botanical-forum.be 
sion submits a report on the advisability of establishing specific rules including, where appropriate, positive lists on categories of nutrients or substances with a nutritional or physiological effect.

(4) Regulations on nutrition and health claims (NHCR) [5] and on the addition of vitamins and minerals and certain other substances to foods (AVMOSR) [6] were adopted on October 12, 2006, and are due for publication in the Official Journal.

In view of these developments, this article explores the scientific basis for the use of botanicals in food supplements and the need for safety evaluation and claims substantiation as guidance to industry, scientific research institutions and legislators.

It discusses how to clarify the differentiation between the use of botanicals for medicinal and health-promoting purposes on a scientific basis and the possibility of drawing a clear distinction between the two groups of products based on their characteristics and presentation.

It proposes guidance on the safety assessment and quality evaluation of botanicals used in food supplements in the light of the different approaches described in the scientific literature with particular attention to the concept of long-term use as an integral part of the safety evaluation.

It proposes guidance on claims substantiation for botanical health products, taking into consideration the proposed NHCR, the concept of long-term experience and the use of health claims based on the grading of evidence of product efficacy.

\section{Botanical Food Supplements: Definition and Regulatory Environment}

The legal requirements for the assessment of safety and efficacy differ considerably depending on the regulatory status of a product, i.e. medicinal or food. A medicinal product, intended for the treatment or cure of diseases or to change the way in which the body functions, is based on pre-marketing authorization and end-product control. This makes it possible to validate both the efficacy and the risks of a medicinal product in order to decide whether it should be allowed on the market. Food products as such are not subject to pre-marketing procedures but they have to be in conformity with the food law framework that has been established. This legal framework consists of authorization procedures for additives, novel foods, genetically modified organisms, etc.; maximum limits for residues and contaminants; the general requirement of hygiene and manufacturer responsibility, and a pre-marketing authorization system for the use of nutrition and health claims.

Since the use of botanicals is possible under both medicinal law and food law, it is important to determine first which legal framework would be applicable to an individual product. This is not always easy. The use of botanicals in foodstuffs is well established. It includes use as vegetables and fruits, herbs and spices (e.g. garlic, rosemary, etc.), herbal teas and infusions (camomile, etc.), herbs added to foods and beverages for taste or functional purposes (e.g. guarana, gentian, etc.), botanical food supplements (functional ingredients derived from botanicals, used for their health-promoting properties, e.g. carotenoids, flavonoids, isoflavones, procyanidins, phytosterols, etc.).

Botanical food supplements can be defined as food supplements under the FSD, consisting of or containing botanical ingredients and that may make a health claim on the relationship that exists between the botanical ingredient and health. Such botanical ingredients may be whole botanicals in comminuted or powdered form, or obtained by traditional techniques such as extraction, distillation, expression, fractionation, purification, concentration or fermentation. Such products may at first glance look very similar to medicinal products, but the intended use is quite different. While medicinal products are intended to prevent (e.g. vaccines) or treat a disease or modify the way in which the body functions (e.g. anesthetics, contraceptives, etc.), food supplements are intended to complement the diet with substances possessing health-maintenance or promoting properties. The most practical element to distinguish between both classes of products to determine what legal framework is applicable is therefore their intended use. This is especially relevant for those botanicals that are used both in food supplements and medicinal products, the so-called ambivalent plants, e.g. garlic, hawthorn, ginkgo, artichoke, etc.

The key issue therefore becomes at what point is the action of a botanical no longer health-promoting but becoming medicinal? In scientific terms, this is a difficult question to address. The actions of most substances on the body are part of a continuum and gradually change in response to dose, form, individual susceptibility and circumstances of administration (fig. 1). The regulatory exercise to distinguish between medicinal effects and health effects therefore involves a somewhat artificial classification break based on the concentration of active principles or their posology. 
Fig. 1. Actions of a substance on the body.

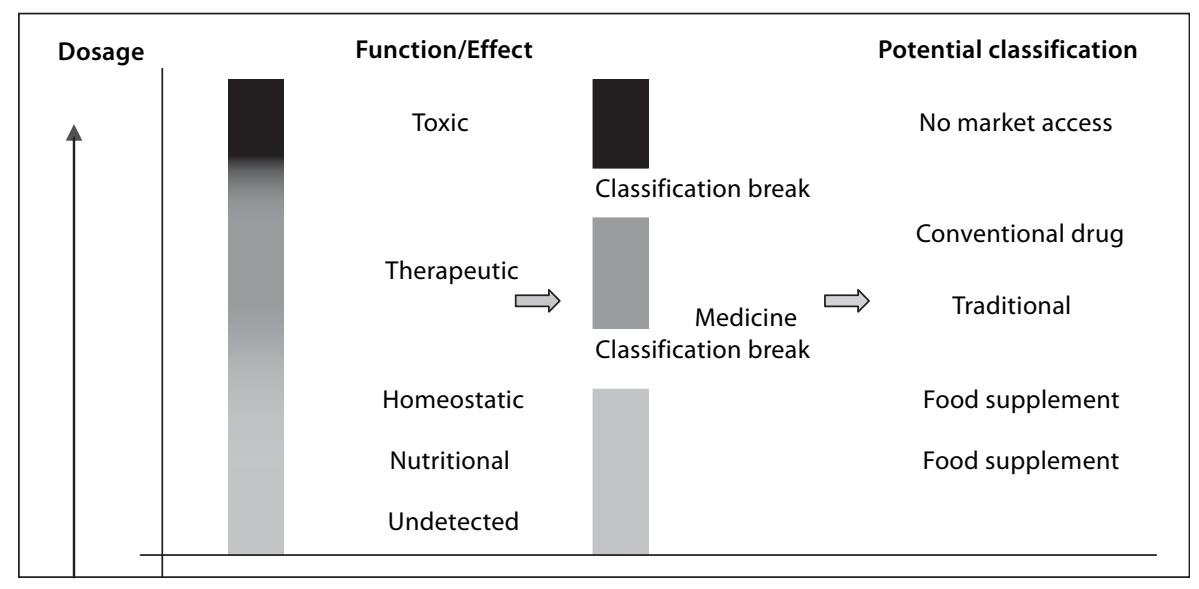

Table 1. Legal definition of food supplement and medicinal product

Definition of food supplement (Directive 2002/46/EEC):

Foodstuffs the purpose of which is to supplement the normal diet and which are concentrated sources of nutrients or other substances with a nutritional or physiological effect, alone or in combination, marketed in dose form, namely forms such as capsules, pastilles, tablets, pills and other similar forms, sachets of powder, ampoules of liquids, drop-dispensing bottles, and other similar forms of liquids and powders designed to be taken in measured small unit quantities.

Definition of medicinal product (Directive 2001/83, as amended by Directive 2004/27):

Any substance or combination of substance presented as having properties for treating or preventing disease in human beings;

or

Any substance or combination of substances which may be used in or administered to human beings either with a view to restoring, correcting or modifying physiological functions by exerting a pharmacological, immunological or metabolic action, or to making a medical diagnosis.

The respective definitions of the two regulatory categories (food supplements and medicinal products) should be able to give guidance but, as is apparent from table 1, they leave quite some room for overlap. However, for the key terms which seem essential for making the distinction between medicinal products and foodstuffs (e.g., 'disease', 'physiological', 'pharmacological', 'metabolic', etc.) no precise definition is given in legislation. And even if there were such definitions they would not provide much further clarity from a scientific point of view.

The definition of a medicinal product is included in the Medicinal Product Directive (MPD) 2001/83/EC [7], as amended by Directive 2004/27/EC [8]. It is indeed so broad because it is designed to cover a very wide range of different medicinal products, including gene therapy, cell therapies, xenogenic somatic therapy, radiopharmaceutical products and certain medicinal products for topical use, etc. However, such a broad definition runs the risk of overriding a number of product categories with their own separate legal framework (e.g. food supplements, foods bearing health claims, cosmetics, medical devices). That this was not the intention is specified in recital 7 of the MPD, which states that 'Where a product comes clearly under the definition of other product categories, in particular food, food supplements, medical devices, biocides or cosmetics, this (i.e. the medicinal product) directive should not apply'. This is consistent with the view, expressed on several occasions by the European Commission, that it is not the intention of medicinal law to expand the registration procedure onto the field of foodstuffs, but merely to be able to include novel medicinal therapies.

European medicinal product legislation exists since 1965, so the borderline with other product categories is very old and quite a few disputes have been settled before the European Court of Justice ${ }^{2}$ (ECJ) [9-15]. In summary, the ECJ concluded that it is for the national courts to determine on a case-by-case basis the classification of each product with regard to its pharmacological properties as they may be ascertained in the current state of scientific knowledge, to the way in which it is used, to the extent to which it is sold, its familiarity to the consumer, and the risks which its use might entail. This means a case-by-

2 The text of court cases of the European Court of Justice are easily accessible through the CURIA website: http://www.curia.eu.int/en 
case assessment and confirms that no ingredient or group of ingredients as such can be judged to be medicinal by function without considering the products they are used in. This is also confirmed by the recent introduction in the MPD of an article stating that in cases of doubt, where, taking into account all its characteristics, a product may fall within the definition of a "medicinal product" and within the definition of a product covered by other Community legislation the provisions of the MPD shall apply' [8]. The scope of this provision is firmly limited to 'cases of doubt' and is restricted to individual products. It confirms the case-by-case assessment approach as established by case law, taking into consideration all the product characteristics which refer to the criteria that have been identified by the ECJ in previous court cases. Or, in other words, food ingredients or substances used in foods cannot by virtue of the definition of medicinal product be considered to fall under medicinal law; only individual products containing them could.

The ECJ also offers clarification on the pharmacological properties, i.e. the nature of the effect that a substance should possess in order to make medicinal product legislation apply. While the ECJ is clearly of the opinion that the scope of the terms 'restoring, correcting or modifying physiological functions' is broader than only 'treating or preventing disease', it nevertheless warns against a literal interpretation which would not be in line with what the legislator intended. The effect should be significant and a certain therapeutic activity would be required. The ECJ specifies that medicinal law cannot encompass substances which, while having an effect on the human body, do not significantly affect the metabolism and thus do not strictly modify the way in which it functions. An essential requirement for the interpretation of this functional requirement is therefore the presence of a medicinal purpose or therapeutic activity. If not, products such as soaps and surgical antiseptics could both be considered medicinal products on the basis of their antibacterial and antiseptic effects, where the first clearly has no medicinal purpose and the second clearly has. The MPD itself specifies that a marketing authorization is to be refused if '[...] its therapeutic efficacy is lacking or is insufficiently substantiated [...]' (Directive 2001/83/EC art 26). How then would it be possible to consider a product that has substantiated physiological effects but no therapeutic efficacy to fall under medicinal law, subject to the registration procedure if in that case a license would automatically have to be refused [16]?

These elaborations, be it nice and interesting for lawyers, all fail to address the fundamental question how to assess the nature of the pharmacological properties that would be required to trigger medicinal product legislation. A pragmatic model was proposed by the European Training and Assessment Foundation (ETAF) group in 2002 [17]. It starts from the intended use of the individual product, as the entry point to determine the applicable legislation for a given product. If the intended use of the product is medicinal, i.e. involving therapeutic action, effects on diseases and changes in physiological processes, then medicinal legislation will apply to verify safety and efficacy in relation to the intended use. If efficacy is lacking, a license will be refused. If the intended use is healthpromoting, i.e. involving function-enhancing properties, effects on health and the proper functioning of normal physiological processes, illustrated through the making of a health claim, then the food legal framework will apply. And the effect in relation to the claim will be considered under the NHCR.

An interesting approach to specify more precisely what could be considered as health-enhancing properties can be found in the recent Council of Europe guidelines on botanical food supplements [18]. The Council of Europe describes 'physiology as the science that studies the generally normal functions, organ properties and tissues of living beings. Physiological activities in the context of a healthy individual are the normal functions in the body, which keep the body going on. Contrary to medicines that concern disease, food supplements must therefore be designed with the beneficial aim in mind of ensuring the maintenance and metabolic and physiological functioning of an individual in good health. This is the principle of homeostasis. As a matter of fact, homeostasis is defined as the bodily situation of a healthy individual in whom his physiological activities are functioning in between the limits considered as normal' (our emphasis).

The reference to physiological functions as the normal functions in the body, which keep the body going and are responsible for homeostasis can be regarded as an important benchmark to judge the effects of a botanical food supplement on the body and differentiate it from a medicinal effect. The boundaries of homeostasis can be considered the boundaries of normal and healthy functioning of the body, taking into consideration the inter-individual variability around the physiological equilibrium. Keeping the body within these limits and preventing the body from going outside these boundaries would be the subject of botanical food supplements. Bringing an aberrant system back into a status of homeostasis would be the realm of a therapeutic or medicinal action.

Ann Nutr Metab 2006;50:538-554 


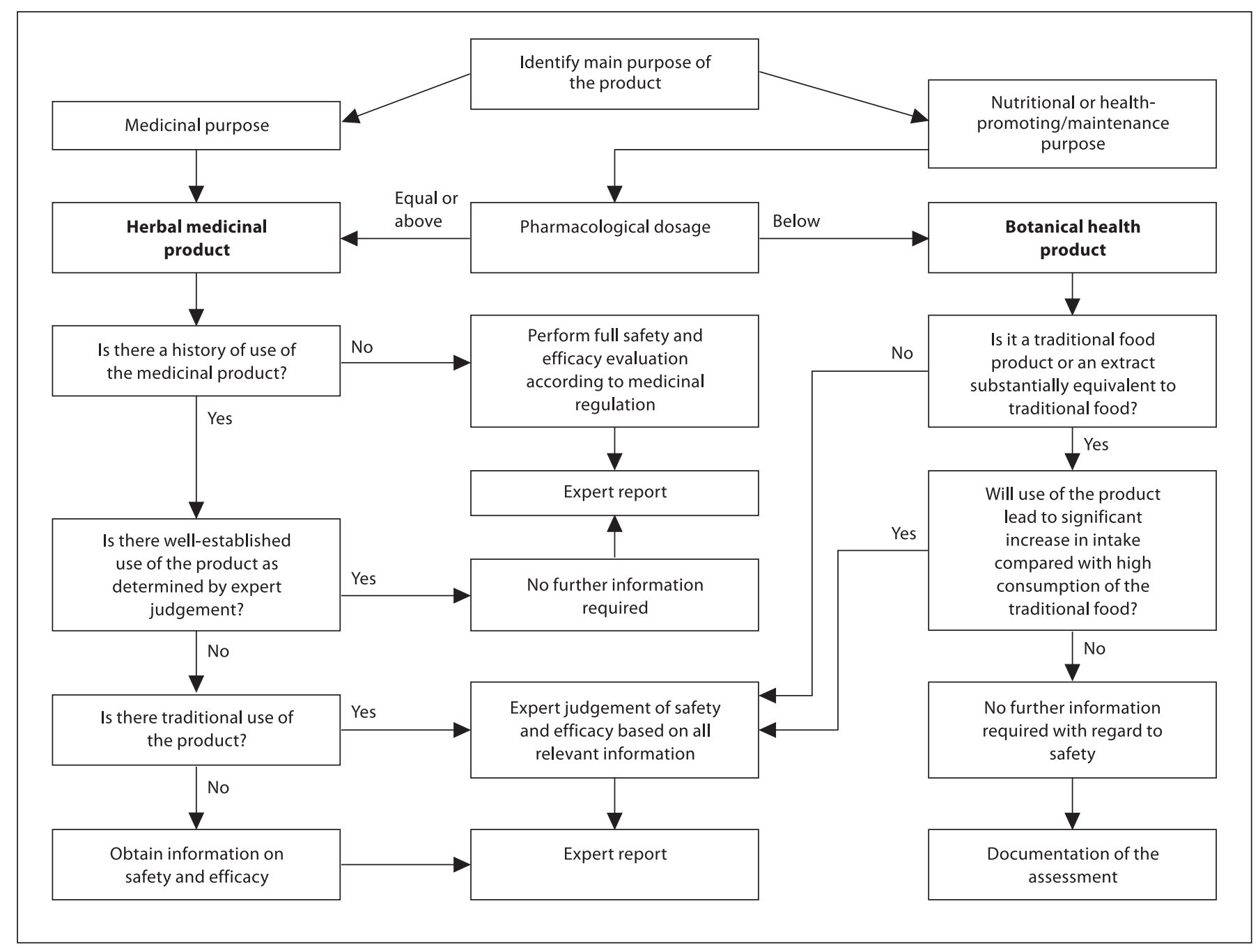

Fig. 2. Decision tree for the assessment of safety and efficacy of botanical products as presented by the ETAF group [17].

Therefore, from a legal and scientific perspective, the following approach with regard to the scope of the different product categories could be defended.

Food supplements are intended to be taken with the aim to improve, support or optimize the normal physiological processes within the boundaries of homeostasis without modifying, altering or blocking any physiological process outside these boundaries. This could be referred to as 'physiological activity'.

Medicinal products are intended to be taken with the aim to bring back into 'the normal average limits' any physiological process which is out of normality and hence considered as pathological. Also products which block or alter normal physiological processes in unphysiological way are medicines (e.g. contraceptives, anaesthetics, ...).
In this respect it would be appropriate to term this 'therapeutic activity'.

Evaluation of the status of a given product is done on a case-by-case basis. This principle does not allow classification of a specific botanical as such, but should always be applied to the intended use of a specific product containing the botanical at specific conditions/dosage. But the concept of homeostasis would also enable it to be determined under what conditions or dose the activity of a botanical would become medicinal, i.e. it could be the benchmark for determining a therapeutic dose.

It is therefore suggested as a possible way forward that work is undertaken to investigate the setting of maximum levels for active substances to be included in botanical food supplements. If such maximum levels are re- 


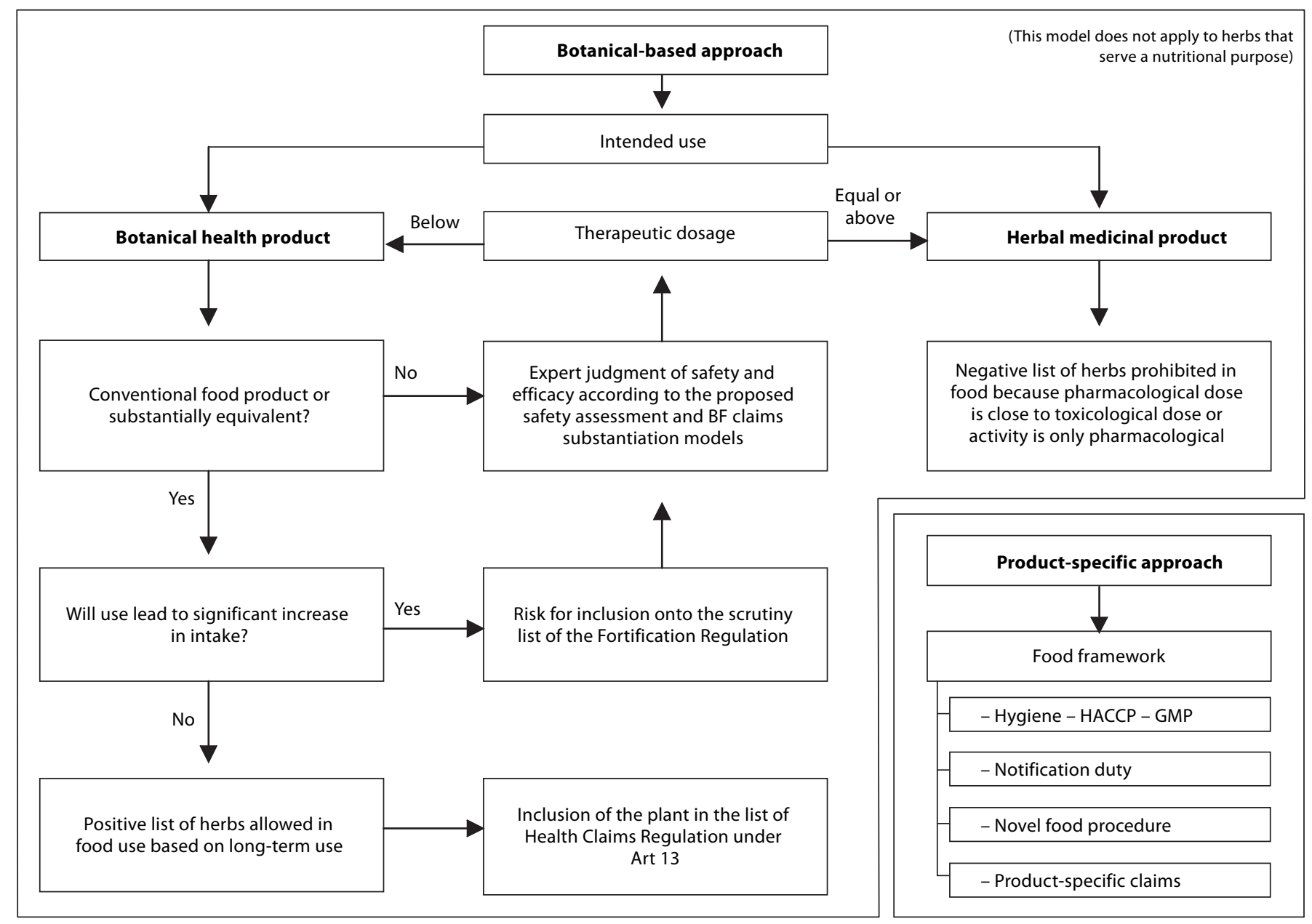

Fig. 3. Proposed decision tree for the assessment of safety and efficacy of botanical products.

duced to levels below the recognized proven therapeutic active level, based on clinical evidence, this would provide a cutoff point for such substances to be used in botanical food supplements.

Of course, such cut-off values would need to take into consideration the safety and scientific validity of the health claim. Such an exercise should be undertaken on a case-by-case basis for each botanical and the physiologically active level should be set at a sufficiently significant level to satisfy the health-promotional benefits that would still be expected. The model of homeostasis could assist in determining such cutoff points for the effects of individual botanicals.

The ETAF group came to the conclusion that botanical products can and should be regulated under either the current food or medicinal regulations as appropriate and proposed a decision tree with the intended use of the product and its pharmacological activity as the key pivotal aspects for classification under one or the other legal framework (fig. 2).

At the time the ETAF model was presented, three future steps in food regulation that would have a considerable impact on botanical food supplements were not known. These are the NHCR, which will deal with claims substantiation and therefore efficacy; the AVMOSR, which will deal selectively with a number of safety issues; and the report on the advisability of establishing specific rules on other substances with a nutritional or physiological effect, provided for by the FSD.

These elements can now be integrated to complete the ETAF model for botanical food supplements (fig. 3).

In this respect a distinction should be made between a botanical-based and a product-specific approach. Food law is a framework where general legal requirements are 
specified in a horizontal way and have to be applied to individual products. A botanical-based approach is therefore essential to establish general criteria for the use of botanical ingredients in individual products. But a product-specific approach is needed to apply these general requirements to individual products. This includes production-related quality and safety aspects, such as the application of hygiene legislation, notifications, productspecific novel foods applications, product-specific health claims approval, etc. These aspects are addressed in the framework of general food law for all products and, if appropriate, specific guidelines on how to apply them to botanical food supplements could be developed.

\section{Safety Evaluation of Botanical Food Supplements}

The ETAF group concluded that:

(1) When a herbal product at a defined dosage can be proven to have a clear medicinal effect for a defined medicinal purpose and presented with a medicinal claim, the product must be registered as a medicine.

(2) If a product is used for nutritional or health promoting/maintenance purposes and is clearly below the dosage used for medicinal purposes, it can be marketed under food law only if: (a) the botanical product is safe (e.g. positive list); (b) the quality of the botanical product is guaranteed and the botanical product is produced under good manufacturing practice conditions appropriate for food, and (c) no medicinal claim is given.

The extension of the ETAF model with the recent legal developments allows botanical food supplements to be classified into four categories of products depending on their safety:

(1) Botanicals whose use in foods would be dangerous because of their toxic or pharmacologic effects. Such botanicals would be eligible for inclusion in a negative list.

(2) Botanicals with nonconventional food or food supplement use that should be subjected to a full safety assessment according to the proposed model.

(3) Botanicals with conventional food or food supplement use, but used at concentrations which would result in intake levels higher than under normal conditions of use. Such botanicals could be included in the scrutiny list provided for by chapter 3 of the AVMOSR.

(4) Botanicals that can be generally considered to be safe under their conditions of use in food and food supplements.

This model would not apply to botanicals whose use in foods serve a nutritional purpose, e.g. fruits and veg- etables, and herbs and spices used for their seasoning properties.

\section{Dangerous Plants}

A number of botanicals possess effects that pose a health hazard for the consumer. These botanicals should not be used in foods and their use for medicinal purposes should be well controlled. In 2005 the European Food Safety Authority (EFSA) published a discussion paper on botanicals and botanical preparations [19]. They concluded that the compilation of a list of plants or parts of plants which should not be used or could be put under scrutiny because of the presence of undesirable substances, especially if effective reduction or removal of such substances cannot be ensured, could be considered. Such lists already exist in a number of Member States [1].

It must be emphasized, however, that the use of negative lists should be considered with care since it would preclude use of the botanical entity for all applications, whereas the safety of derivatives, extracts or isolates can frequently be demonstrated.

(1) The toxic component or adverse effect may be associated only with one of the plant components (e.g. the leaves, fruits, seeds, roots, etc.).

(2) A plant may be used as raw material for the production of additives, flavors, and functional food ingredients using processing techniques that remove the toxic or undesirable component.

(3) A plant may be subjected to a treatment that inactivates or destroys the toxic or undesirable component.

(4) A plant may be rendered harmful by its specific extraction process, e.g. in the case harmful effects are observed with the use of organic extractions where no such effects are observed in the case of aqueous extracts.

(5) A plant may show harmful effects at high doses whereas this is not the case at a lower dose. Assessment of the dose and ways in which to manage that such doses are not exceeded should be part of the exercise. The setting of maximal values may in this respect be a better way than simply including the botanical on the negative list.

(6) A plant may show undesirable effects when used in an inappropriate way, by certain population groups or by interaction with other foods or medicinal products. In such a case the use of appropriate warning statements could be envisaged.

(7) The toxic or undesirable effect may be restricted to one species of the whole plant family. In such a case it should be addressed what methodology or measures would be required to make sure that the toxic species can 
be distinguished and separated from other members of the same family and contamination can be avoided.

That this is a delicate exercise is illustrated by the fact that some plants figure on negative lists in some countries but not in others. It is clear that as with quite a number of other food components, certain botanicals can have side effects and such side effects have to be balanced against the beneficial health effects. It should be emphasized that side effects do not represent safety issues. Side effects are not related to toxic or harmful effects for consumer health. They are effects associated with the use of a botanical food supplement consumers may or may not choose to accept when fully informed. Aspects including population group, frequency, dose, quality, relative risk, conditions of use, etc., will need to be addressed in order to assess the relevance of the potential side effects in the light of the expected benefit.

In order to be able to prepare a negative list in an objective way, based on risk analysis, the following methodology is being proposed.

Step 1: To work on a compilation of the negative lists, based on already developed negative lists by authorities in order to see what plants or parts of plants have been included and for what reasons.

Step 2: To identify those botanicals that figure on a number of lists and assess if they would be eligible to be included in a EU-wide list.

Step 3: To identify those plants where there is no consensus on the approach and evaluate the safety assessment through the proposed safety assessment model in order to judge whether there is sufficient reason to include such plants on the list.

\section{Botanicals Not Conventionally Used in Foods and Food Supplements}

Many botanical products have a long history of safe use for health maintenance purpose in, e.g., herbal teas, food supplements, although there is only limited published scientific literature available. Such a history of safe use is based on decades of knowledge and experience. Many approaches are adopted by the Member States to regulate botanical food supplements. None of them is requesting a full safety assessment of these substances, given their long-term safe usage.

A number of plants do not have such history of use and concern is raised about safety aspects. In such case, expert judgment on safety may be required. If such botanicals have not been used to a significant degree prior to May 1997 in the European Union, such botanicals would have to undergo novel foods assessment according to the
Novel Foods Regulation 258/97 [20]. The Scientific Committee of Food published detailed guidelines on the application of a novel foods dossier [21].

A number of guidance documents on the safety assessment of botanicals and botanical preparations for use in food and food supplements have been published by the International Life Science Institute (ILSI) [22], the French Food Safety Agency (AFSSA) [23], and the Council of Europe [18]. The ILSI guidance note is based on a productspecific model. It provides all the 'essential elements' to consider (e.g. product specifications, composition and characterization of standardized and authentic material, documented history of use and comparison to existing products), description of the intended use and consequent exposure) as a strong basis for safety and risk evaluation for individual products. The main feature is the presentation of a 'decision tree' as an aid to determine the extent of the data requirement. This decision tree starts from the question if the botanical has indeed conventional or traditional food use or not.

In order to address the safety aspects of those botanicals the following working plan is proposed.

Step 1: Identify those botanicals that have no conventional food use. Such an inventory would only relate to the botanical itself, not to extracts or isolates. It would be compiled taking into consideration: (1) the current legal status of the herb in different Member States, and (2) established sources of information on the safety of the herb, i.e. the US Food and Drug Administration (FDA) [24], World Health Organization (WHO) [25], US Agency for Healthcare Research and Quality (AHRQ) [26], US Pharmacopoeia (USP-NF) [27], US Pharmacopoeia Dietary Supplement Verification Program (USP-DSVP) [28], American Herbal Pharmacopoeia (AHP) [29], American Herbal Products Association (AHPA) [30], American College of Clinical Pharmacy, Natural Medicines Comprehensive Database (NMCD) [31], Bundesinstitut für Arzneimittel und Medizinprodukte, Kommission E [32], Health Canada National Health Products Directorate (NHP) [33], European Cooperative on Phytotherapy (ESCOP) [34], European Pharmacopeia Commission (EPC) [35], British Herbal Medicine Association (BHMA) [36], Physician's Desk Reference (PDR) [37], etc.

Of particular importance for the establishment of such an inventory will be following restraining criteria: (1) regulatory, e.g. check of novel foods status, use of the botanical for medicinal purposes, etc.; (2) quality aspects, e.g. specification of the source, plant part, etc.; (3) negative lists, is the botanical already included in negative lists including the reasons for such inclusion, etc., and 
Table 2. Council of Europe proposed outline of a monograph for the assessment of the value and safety of a plant

Botanical data: State usage if there is a difference between

food supplements and medicines

Complete scientific name and family

Synonym and common name

Part used

Geographical origin and production

Monographs available (pharmacopoeias, ESCOP, WHO, etc.)

Risks of adulteration by a toxic neighboring species

Chemical constituents: State use if there is a difference between food supplements and medicines

Molecules present classified by groups and chemical affinities

(e.g. flavonoid, alkaloid, etc.)

Quantitative incidence (methods?)

Possible influence of cultivation practices on composition

Pharmacology: Where possible, indicate source references Human pharmacoclinical: properties described,

galenic forms used, method of administration, dosages

Experimental in vivo: properties described, animal species,

galenic forms used, dosage, method of administration

Experimental in vitro: properties described on single organs and/

or cellular impact etc., galenic forms used, dosages, solvents

Molecular: nature of tested molecule, molecular targets,

experimental conditions and results

Pharmacokinetic data

Toxicology: Where possible, indicate source references

Symptomatology described, galenic forms and/or substances

used, doses, etc.

Available drug-monitoring data

Overdoses

Normal conditions of use: State usage if there is a difference between food supplements and medicines

Galenic forms: powder, type of extract (totum and/or specific)

Indications and doses used in the form of medicines

Claims and doses proposed in the form of food supplements

Decline in use and country of use

Identification of warning points

Proven or potential toxicity of constituents (carcinogenicity, mutagenicity, teratogenicity, allergenicity, etc.) or of molecular interactions

Possible side effects

Possible counter-indications (pregnancy, breast-feeding,

pediatric use, conduct of machines, etc.)

Risks connected with galenic forms (extracts)

Interactions between medicines

Questions concerning the claim

Bibliography
(4) compositional, does the product contain toxic constituents, allergens, etc.

Step 2: Apply the ILSI model for safety evaluation of these botanicals.

Step 3: On the basis of this evaluation, determine the appropriate conditions for use in botanical food supplements (i.e. under food use), including as appropriate: (1) the determination of therapeutic active dose; (2) imposing specific restrictions of conditions for its manufacturing process and use in the final product; (3) determine purity criteria and/or maximal levels for constituents, contaminants, residues, and (4) appropriate labeling requirements, including specific conditions of use and warning statements as appropriate.

For the way in which the necessary documentation could be compiled, the Council of Europe guidance documentation may be appropriate (table 2).

\section{Botanicals Conventionally Used in Foods and Food Supplements, but at Intake Substantially Higher than Conventional}

History of safe use in foods and food supplements is related to conventional conditions of use. If such botanicals are used at a given point under conditions that would result in significantly higher intakes than would be considered conventional, safety concerns may arise. It is to this effect that the proposed AVMOSR contains provisions to put substances for which safety risks may be identified or suspected upon lists that either would prohibit the further use of these substances, impose restrictions on the use or requests manufacturers to submit data supporting the safe use of the substance under the specified conditions of use. In such a case the data identified by the ILSI model would need to be available for submission to EFSA under this procedure to justify the safety of the use under such new conditions.

The ETAF group proposed the establishment of a positive list of botanicals whose use in foods would be safe. Given the approach of the scrutiny list included in the AVMOBR, such a positive list should be restricted to those botanicals and the conditions of use that are at the origin of the safety concern.

\section{Botanicals Conventionally Used in Foods and Food}

Supplements under Conventional Conditions of Use

Botanicals whose use is undisputed in foods and food supplements should be subject to no further assessment as long as they are presented and formulated for healthmaintenance or promoting properties. The NHCR provides for the establishment of a list with health claims that 
are based on generally accepted scientific evidence. This implies that a list with botanicals associated with such claims will be established de facto. This would not, however, preclude the further use of botanicals without associated claims or products carrying a product-specific approved claim.

\section{Product-Specific Quality Aspects}

Botanical products, containing botanical ingredients, should be manufactured and controlled by the manufacturer under the responsibilities imposed by the GFLR. The ingredients used should be well identified and characterized. Appropriate and well-documented management of specification, processing, quality testing (particularly in relation to identification and purity), and standardization are of paramount importance in the production of safe botanical food supplements. Or as EFSA puts it: 'As purity specifications for all botanicals and botanical preparations are very difficult to define, the development of ad hoc manufacturing guidelines, could be considered in order to improve their characterization and safety. Experience already existing in the pharmaceutical sector could be helpful to this end.' Quite a number of guidelines are available covering good agricultural practices, good manufacturing practice and quality control of botanical products, e.g. the European CPMP Note for Guidance Quality of Herbal Medicinal Products (CPMP/ QWP/2819/00) [38], the CPMP Note for Guidance on Specifications: Test Procedures and Acceptance Criteria for Herbal Drugs, Herbal Drug Preparations and Herbal Medicinal Products (CPMP/QWP/2820/00) [39], and several WHO guidelines on the manufacturing of herbal medicinal products and on quality and good agricultural and collection practices for medicinal plants [40]. These guidelines provide a well-defined framework for quality testing and can guarantee a reproducible quality of the botanical products.

The concepts of quality control and quality assurance should by analogy apply to botanical products evaluated under food law. But because they are produced in conformity with food law regulations, associated with lower safety concerns and weaker claims, there is no need to apply medicinal product standards. The method of production and the specifications must guarantee that the product is appropriate for the intended use as a botanical food supplement. The choice and extent of certain quality tests may depend on parameters such as adherence or non-adherence to Good Agricultural Practices. Under food law, special emphasis should be given to characteristics directly related to safety such as the proper definition and identification of the starting material, e.g. confusion with other plant species, plant part, etc.; testing of impurities, contaminants and, if applicable, intrinsic natural toxicants, e.g. pyrrolizidine alkaloids; management of the production process and variability; standardization of the final product. Modalities of these elements are very well presented in the ILSI and Council of Europe guidance documents. Within the framework of quality control/assurance, the method of production and the specifications applied to a botanical product should in that way guarantee that it is appropriate for the intended use.

An important aspect of general food law is the socalled notification duty, imposed by article 19 of the GFLR. This requirement accommodates for routine inmarket surveillance, in combination with the Rapid Alert System for Food and Feed [41] connecting all the European safety authorities of the Member States, and provides a powerful tool to identify unexpected untoward effects of specific botanical food supplements at an early stage and take appropriate actions.

\section{Claim Substantiation}

An important reason for the use of many botanicals or botanical ingredients in foods and food supplements is their health-enhancing properties. It is therefore essential that such properties are communicated correctly and truthfully to the consumer. They must be based on evidence that is generally accepted and the effect must be valid for the final product in relation to its composition, dose and instructions of use.

To be in conformity with food legislation and to respect the legal distinction with medicinal products, care should be taken that the product does not claim or possess properties of preventing, treating or curing a human disease.

In June 2003 the European Commission presented to the Council and European Parliament the NHCR proposal. This proposal was adopted by the Council on October 12, 2006. It is applicable to all foods eligible for making nutrition and health claims (including reduction of disease risk claims), and therefore also to botanicals used in foods and food supplements. The basic principle of this legislation is that all health claims will have to be approved prior to marketing by a procedure involving a scientific opinion by the EFSA and a commitology decision by the European Commission, i.e., a joint decision taken by representatives of all Member States. 
The NHCR foresees two kinds of pre-market approval. The first procedure will lead to a list of claims describing or referring to the role of a nutrient or other substance in growth, development and the functions of the body. The second procedure, a genuine authorization procedure through EFSA (either full or accelerated), concerns innovative, product-specific claims and reduction of disease risk claims.

\section{Essential Requirements for Health Claim Substantiation}

The regulation does not lay down detailed criteria or requirements for the scientific data or the level of scientific substantiation that should be available to underpin a specific product-specific health claim. But there are other sources that can assist in identifying the requirements for scientific data. With respect to the scientific assessment of health claims for regular foods, the PASSCLAIM project has established criteria for the scientific substantiation $[42,43]$. It would therefore be advisable that for the scientific substantiation of product-specific claims, i.e. claims involving testing on the actual product, the criteria elaborated by the PASSCLAIM initiative are taken into consideration.

Since product-specific health claims are relevant for individual (groups of) products (foodstuffs or food ingredients), it is the primary responsibility of the manufacturer to gather the necessary scientific data and knowledge underlying his product and conduct the supporting studies as appropriate. The preparation of a technical document or scientific dossier will involve collecting information on the quality, safety and efficacy aspects of the product itself, i.e. herbal source (name and characteristics, scientific name, part of plant used and its condition, preparation and processing, characterization of compounds of the plant material that is biologically or physiologically active); quality specifications (authenticity, purity, assay of active fractions, conditions for packaging, labeling and storage); name and formula of the product (single ingredient, compound ingredients, quantity/dose) [18].

\section{Value of Long-Term Experience}

Botanical food supplements are an important category of products with specific particularities in this respect. They have been used for a very long time, and prolonged and apparently uneventful use of herbal products may offer testimony of their safety and efficacy. This has been the basis for the elaboration on European level of a legislative framework relating to traditional herbal medicinal products. The argumentation is that a significant number of medicinal products, despite their long tradition, do not fulfill the requirements of a well-established medicinal use with recognized efficacy and an acceptable level of safety and are not eligible for marketing authorization (Directive 2004/24, Recital 3) [2]. It was therefore judged reasonable in view of the particular characteristics of these medicinal products, especially their long tradition, to provide a special, simplified registration procedure to be used only where no marketing authorization can be obtained pursuant to Directive 2001/83/EC, in particular because of a lack of sufficient scientific literature demonstrating a well-established medicinal use with recognized efficacy and an acceptable level of safety. The long tradition of the medicinal product makes it possible to reduce the need for clinical trials, in so far as the efficacy of the medicinal product is plausible on the basis of long-standing use and experience. Pre-clinical tests do not seem necessary where, on the basis of information on its traditional use, the medicinal product proves not to be harmful in specified conditions of use.

The above concerns medicinal products, i.e. products presented as having properties for treating or preventing disease in human beings. Botanical food supplements are products that are presented as having beneficial properties in relation to health, which would require a proportionally lower degree of scientific substantiation requirements. Respect for the knowledge of traditional or longterm use and experience of a botanical both in the medicinal as well as in the food field is therefore also an important aspect to be taken into consideration in the scientific assessment of health claims for botanical food supplements regulated under food law, when files are composed for specific botanicals with the aim of including these into the list provided for by the NHCR or when scientific research is proposed, prepared and conducted.

\section{Emerging Science}

The preamble of the proposed EU claims legislation states that health claims should only be authorized by EFSA after scientific assessment of the highest possible standard. Whilst no one would disagree with the basic principles of scientific substantiation, there is major concern on the part of the scientific community and industry on how to accommodate emerging science, i.e. claims that are (not yet) subject to full scientific consensus [44].

In the field of medicinal products different grades of evidence are recognized, e.g. guidance on safety and efficacy required for well-established herbal medicinal products in bibliographic applications, which are based on criteria developed by the US Agency for Health Care Policy 


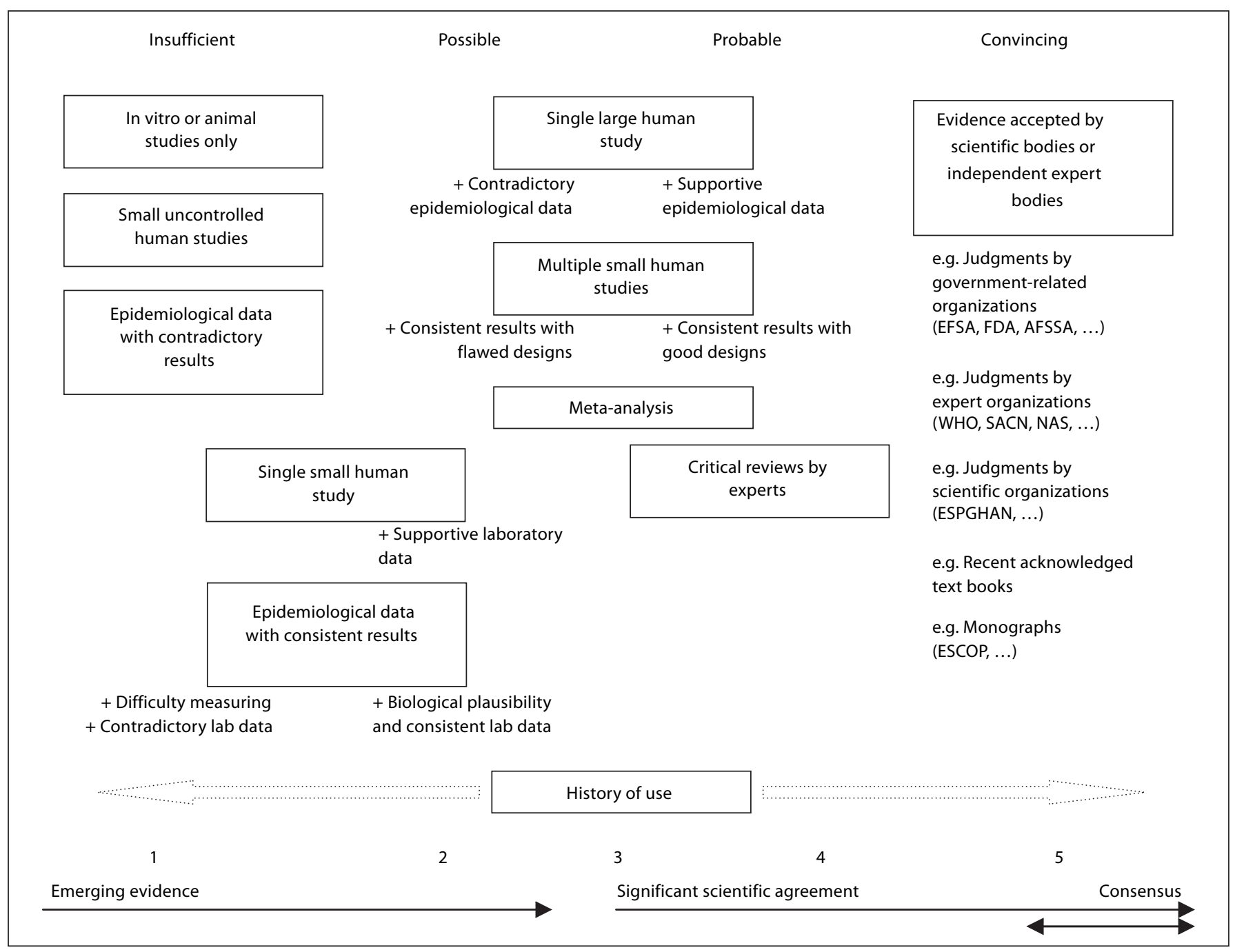

Fig. 4. Grading of evidence. Adapted from Richardson [44].

and Research and WHO $[45,46]$. This is to provide a system to accommodate situations whereby it would not be necessary to provide results of pre-clinical tests or the results of clinical trials when it can be demonstrated by detailed references to published scientific literature that the constituent or the constituents of the medicinal product has or have a well-established medicinal use with recognized efficacy and an acceptable level of safety. The guidance on the grading of evidence is currently being adapted to include traditional use as a further grade of evidence, i.e. in so far as the efficacy of the medicinal product is plausible on the basis of long-standing use and experience, in the absence of supportive scientific evidence.

In the food field, WHO and the World Cancer Research Fund have established four grades of evidence: 'convincing', 'probable', 'possible' and 'insufficient' [47]. These definitions are defined for observational/epidemiological studies, but they need to be developed to cover the interpretation of other human studies and areas of supporting evidence, including animal and in vitro studies. The USA has already adopted an approach that recognizes different grades of evidence [48]. The EU has not yet considered the concept of grades of evidence in the field of health claims. It is crucial to support scientific initiatives to find an approach where the term 'generally accepted scientific evidence' includes not only generic or well-established linkages between a food or a food component and a health benefit, but defines 'generally accepted scientific evidence' to take into account the overall concept of the grades of evidence and the balance of prob- 
abilities that an association between a food or a food component and a health benefit will be refined (not reversed) by subsequent scientific research [40].

It would therefore seem appropriate that also in the field of health claims made on foods (including botanical food supplements) there be a coordinated effort to promote the concept of appropriate grades of evidence from the scientific perspective, taking into consideration also emerging science and/or long-term use and experience (fig. 4).

\section{Communication of the Health Benefit}

It is clear that the grade of evidence underlying a claimed effect should be communicated to the consumer in order to allow him to choose the product in full knowledge of all facts. This would require the acceptance of suitable wording to allow communication of claims in terms consumers can understand. The USA has standardized wording for qualified health claims, and this approach could be adapted for the development of an EU position.

Although there are concerns that words such as 'may' and 'might' may be misleading based on some consumer research, it is worth considering the use and definition of such modal verbs to reflect the strength of the evidence, especially in the public interest and when there are no controls over statements/articles in the press and magazines. Research is required in the different EU languages to explore and develop appropriate wordings depending on the level of certainty of the scientific evidence. If the levels of evidence are decided and defined more closely, the basis for scientific substantiation and the appropriate wording would enable communications to be understood and trusted by consumers.

Another option worthwhile discussing in the framework of the European legislation would be to put a disclaimer on products that have not met the strict requirements of the EFSA authorization procedure, such as: 'the effects claimed for this product have not been assessed by EFSA'. Something similar exists in the USA for claims that have not been approved by the FDA. Manufacturers would still be required to possess the necessary justification underlying the product, but consumers would know that the effects of the product have not been evaluated by EFSA. In the possession of such knowledge they could still opt to purchase and use the product. In order to avoid confusion with (traditional herbal) medicinal products, another disclaimer could be to mention on the label of a botanical food supplement that 'this product is not a medicinal product'.

\section{Generic Health Claims}

'Generic' health claims relate to the effects of diets, food categories, foods, food ingredients or food components, based on generally accepted scientific evidence that is available in the scientific literature, experience, and/or recommendations from national or international public health bodies. The claim need not be tested for the product itself but, when making such a claim, a food or food supplement must respect the general requirements laid down in the NHCR and in particular must contain a sufficient quantity of the constituent to produce the claimed effect.

The application of the NHCR will lead to the establishment of a list of those botanicals whose health effects are based on generally accepted scientific evidence. It is understood that such evidence may include observational data showing long-term experience. The compilation of this list, to be submitted to the Member States for submission to Europe, would need to be undertaken in a concerted way by the industry sectors concerned. A potential proposed methodology to be considered could be the following.

Step 1: Collecting Evidence

The first step would be to collect an inventory of botanicals and the health effects that are recognized by authorities or well-known organizations in the European Union and abroad. Many publications are devoted to the relationship between nutrients and other substances (including botanicals) and their health-promoting effects, including but not limited to textbooks, monographs and scientific studies.

In order to achieve agreement on the required strength of the available evidence a list of authoritative sources can be compiled.

(1) Textbooks: a vast number of textbooks are available that describe the health effects of botanicals based on the available scientific data and traditional and long-term use. Many of these textbooks are considered as reference works by botanical specialists and a recognized list can be compiled.

(2) Monographs: many organizations have drafted monographs with regard to certain botanicals listing, amongst others, the established effects, both medicinal and health effects, and the conditions of use. Authoritative organizations in this respect include WHO [49], ESCOP [34], European Pharmacopeia Commission [35], BHMA (UK) [36], Kommission E (Germany) [32], AFSSA (France) [50], NHPD (Canada) [33], etc.

(3) Scientific studies on a specific botanical. 
Table 3. Proposed format for presenting data on other substances, including botanicals, with selected examples

\begin{tabular}{llllll}
\hline $\begin{array}{l}\text { Food or food component/ } \\
\text { bioactive compound }\end{array}$ & $\begin{array}{l}\text { Health } \\
\text { relationship }\end{array}$ & $\begin{array}{l}\text { Conditions } \\
\text { (if any) }\end{array}$ & $\begin{array}{l}\text { Nature } \\
\text { of evidence } \text { a }^{\mathrm{a}}\end{array}$ & $\begin{array}{l}\text { Level of } \\
\text { evidence }^{\mathrm{a}}\end{array}$ & $\begin{array}{l}\text { Example } \\
\text { of wording }\end{array}$ \\
\hline $\begin{array}{l}\text { Cranberry } \\
\text { (proanthocyanidins) }\end{array}$ & Urinary tract & $\begin{array}{l}200 \mathrm{mg} / \text { day } \\
\text { cranberry juice }\end{array}$ & $\begin{array}{l}\text { Long-term experience } \\
\text { Small number of } \\
\text { clinical trials }\end{array}$ & Probable & Maintains health of urinary tract \\
\hline $\begin{array}{l}\text { Garlic (organo- } \\
\text { sulfur compounds) }\end{array}$ & $\begin{array}{l}\text { Heart and } \\
\text { circulatory } \\
\text { system }\end{array}$ & $600-900 \mathrm{mg} /$ day & $\begin{array}{l}\text { Long-term experience } \\
\text { Clinical trials }\end{array}$ & Probable & $\begin{array}{l}\text { Maintains health of heart and } \\
\text { circulatory system (in relation } \\
\text { to total and LDL cholesterol) }\end{array}$ \\
\hline $\begin{array}{l}\text { Green tea (catechins) } \\
\text { Cancer }\end{array}$ & unknown & Epidemiological & $\begin{array}{l}\text { Possible/ } \\
\text { probable }\end{array}$ & $\begin{array}{l}\text { Reduces risk of certain types of } \\
\text { cancer }\end{array}$ \\
\hline
\end{tabular}

${ }^{a}$ Grades of evidence are provisional and are not based on a systematic review of the science.

${ }^{\mathrm{b}}$ French AFSSA has approved a health claim for cranberry.

Much of the data available may relate to the medicinal effects of botanicals. Such evidence is very valuable to ascertain and enforce the validity of the data underlying the non-medicinal health effects of botanicals (based on the therapeutic dosage).

Step 2: Evaluation of the Data

The data that are collected from step 1 would then have to be evaluated against the methodology as described in the PASSCLAIM project, including appropriate evidence on long-term use and experience. Requirements for substantiation of claims for botanical food supplements should not be higher than those for medicinal products.

Step 3: Determination of the Format and Conditions to Describe the Health Effect

The final step would then consist in formulating in an as exemplary way as possible the health claim permissible for a botanical food supplement, in line with the agreed scientific substantiation and available information on long-term use. Any health claim that refers to the general benefits of food and food components for good health or well-being must be formulated to reflect the specific evidence on which the claim is based and consumer understanding. The health benefits must not go beyond the scope of evidence, confuse or mislead the consumer. Appropriate language could be used to this effect. However, care should be taken that consumers can sufficiently distinguish the difference between herbal medicinal products, serving a therapeutic purpose, and botanical food supplements used for health-promoting purposes.

Use of Botanicals in Food Supplements
A suggested format for summarizing information concerning a herbal and its health benefits is shown in table 3 .

\section{Conclusions}

Botanical food supplements are acknowledged and regulated under food law. All food law provisions apply to their manufacturing, composition and marketing, including the future EU NHCR. Any approach differentiating between botanical material supplied as a food supplement and botanical material supplied as a medicinal product must reflect the complexity and versatility of the botanical starting material. The classification process should be designed to allow access to the market of safe and effective products that may be routinely consumed with a view to promoting health (through homoeostatic activity); at the same time the classification process should provide a mechanism for restricting the availability of unsafe products or products whose use requires additional controls such as would be applied through the medical regulatory environment.

Elements from current EU and national law, scientific papers and other publications can be used to create a legal framework for the safety and efficacy assessment of botanical food supplements in the European Union, respecting current safe practice and innovation. Using arguments from current legislation, ECJ case law, published guidance papers and botanical sciences, it is clear that the differentiation between food and medicinal use of botanicals should be based upon the intended use as repre-

Ann Nutr Metab 2006;50:538-554 
sented by the stated rationale, the way the product is presented and the associated level of active constituents. The intended use of botanical food supplements is to improve, support or optimize the normal physiological processes within the boundaries of homeostasis without modifying, altering or blocking any physiological process outside these boundaries. This is termed physiological activity or effect. Medicinal products are intended to be taken with the aim to bring back into 'the normal average limits' any physiological process which is out of normality and hence considered as pathological. This is termed therapeutic activity or effect.

The general safety evaluation of botanicals proposed is based upon a model that provides the possibility of classifying botanicals under food law into four categories. Botanicals, the use of which in foods and food supplements would be dangerous because of their toxic or pharmacologic effects, would be eligible for inclusion in a negative list based upon lists already established in certain Member States. Botanicals should only be included in such lists if the danger they present cannot be accommodated by processing, imposing conditions of use, or other risk management measures.

Botanicals that are not conventionally used in foods or food supplements would be subjected to a full safety assessment according to criteria proposed, for instance, by ILSI and Council of Europe. Such botanicals should be identified taking into consideration the current legal status of the herb in different Member States and established sources of information on the safety of the herb (i.e. FDA, WHO, AHRQ, USP-NF, USP-DSVP, AHP, AHPA, NMCD, Kommission E, NHPD, ESCOP, EPC, BHMA, PDR, etc.). On the basis of this safety evaluation, for each of these individual herbs, the appropriate conditions for use in botanical food supplements and/or food should be established including as appropriate: the determination of therapeutic active dose; the establishment of specific restrictions or conditions for its manufacturing process and use in the final product; the determination of purity criteria and/or maximal levels for constituents, contaminants, residues; or appropriate labeling requirements, including specific conditions of use and warning statements as appropriate. In the European Union botanicals that were not used to a significant degree in foods or food supplements prior to May 1997 would be subject to novel food approval.

Botanicals with conventional food or food supplement use but used at concentrations which would result in intake levels higher than under normal conditions of use will be subject to the future 'addition of vitamins and minerals and other substances to food' regulation. This will include the provision of safety data on the specific conditions of use to EFSA.

No specific procedure would be required for those botanicals conventionally used in foods or food supplements and a recognized safe use under conventional conditions of use. The future NHCR will provide a framework for validating the substantiation underlying the claims used. Generally recognized claims for specific botanicals will be included on a list. The establishment of this list will require a concerted action of the food supplements industry to bring together the evidence and evaluate it according to specific criteria.

The value of traditional use and long-standing experience is an important element that should be taken in consideration, as is the case with the establishment of efficacy in the traditional herbal medicinal product legislation. Also the concept of grading the evidence is a valuable tool to provide correct information to consumers and stimulate further innovative research. For product-specific claims criteria such as elaborated by the PASSCLAIM initiative are to be taken into consideration.

Apart from the general approach to establishing the general safety of botanicals described above, individual manufacturers have responsibilities to address the safety and efficacy in a product-specific context. These responsibilities are requirements for hygiene, quality testing, manufacturing and processing, and possible productspecific health claims. For these aspects, the general food law regulation lays down the legal framework. This could be complemented by specific guidelines on how to apply these legal requirements in the field of botanicals. In any case, the requirements for botanical food supplements, in relation to safety assessment and proof of efficacy, should not be higher that those applied to herbal medicinal products.

\section{Acknowledgements}

This work was commissioned by the European Botanical Forum and financially supported by the European Federation of Associations of Health Product Manufacturers (EHPM), the European Responsible Nutrition Alliance (ERNA), Natuur- en Gezondheidsproducten Nederland (NPN, NL), Irish Health Trade Association (IHTA, IRE), Ceská Asociace pro Speciální Potraviny (CASP, CS), Federatie van handel en nijverheid in natuur-, reformen dieetwaren in België (NAREDI, BE), Asociación Española de Fabricantes de Preparados Alimenticios Especiales (AFEPADI, ES), Associazione Italiana fra coltivatori, raccoglitori, trasformatori, Importatori, esportatori, grossisti e rappresentanti di case estere di pianti medicinali aromatiche e spezie (ASSOERBE, IT), 
ALLIANCE 7 (FR), Council for Responsible Nutrition (CRN, UK), Amway, Herbalife, Horphag, Ortis, Phytolab, Nu Skin.

The opinions expressed in this paper are those of the authors and members of the Botanical Forum and do not necessarily represent the views of their affiliate companies, institutions or the participants of the Botanical Forum Workshop.

The authors thank the European Botanical Forum and the participants of the workshop for giving them the opportunity to undertake this work and for stimulating discussions.

\section{Appendix}

The European Botanical Forum was created jointly by the $\mathrm{Eu}-$ ropean Federation of Associations of Health Product Manufacturers (EHPM) and the European Responsible Nutrition Alliance (ERNA) with the aim to bring together botanical experts from academia, authorities and industry to discuss the regulatory and scientific aspects of botanical food supplements in the European Union.

Participants at the European Botanical Workshop, November 30 to December 1, 2005, Brussels: Prof. Robert Anton, Uni- versité Louis Pasteur, France; Prof. Med. Dr. Åke Bruce, National Food Administration, Sweden; Mr. Patrick Coppens, ERNA, Belgium; Dr. Desmond Corrigan, Trinity College Dublin, Ireland; Ms. Lorène Courrège, EHPM, Belgium; Dr. Fabio d'Atri, European Commission, DG SANCO, Belgium; Ms. Pascale de Gryse, Federal Public Service of Public Health, Food Chain Security and Environment, Belgium; Dr. Luc Delmulle, ORTIS, Belgium; Prof. Dr. Apr. Frans Gosselinckx, University of Antwerp, Belgium; Mr. Jonathan Griffith, Irish Health Trade Association (IHTA), Ireland; Dr. Om Gulati, Horphag Research, Switzerland; Prof. Dr. Rudolph Hermus, TNO Nutrition \& Food Research, Zeist, the Netherlands; Dr. Márta Horácsek, National Institute of Food Safety and Nutrition, Hungary; Mr. Gert Krabichler, DSM Nutritional Products Europe Ltd., Switzerland; Dr. Manfred Ruthsatz, Innéov, France; Dr. Bruno Scarpa, Ministero della Salute, Italy; Dr. Carlo Sessa, ASSOERBE, Italy; Dr. Hartwig Sievers, Phytolab GmbH, Germany; Prof. Vittorio Silano, Ministry of Health, Italy; Dr. Lucjan Szponar, National Food and Nutrition Institute, Poland; Dr. Marinella Trovato, Società Italiana delle Scienze e delle Tecniche Erboristiche, Italy; Mr. Peter van Doorn, Natuur-\&gezondheidsProducten Nederland (NPN), the Netherlands.

\section{References}

1 European Advisory Services: Marketing Food Supplements, Fortified and Functional Foods in Europe. Report 2005. ISBN 90806995-1-9. www.eas.be

2 Directive 2004/24/EC of the European Parliament and of the Council of 31 March 2004 amending, as regards traditional herbal medicinal products, Directive 2001/83/EC on the Community code relating to medicinal products for human use. Official Journal of the European Union: L183/51, 30 April 2004.

3 Regulation (EC) No. 178/2002 of the European Parliament and of the Council of 28 January 2002 laying down the general principles and requirements of food law, establishing the European Food Safety Authority and laying down procedures in matters of food safety. Official Journal of the European Union: L31/1, 1 February 2002.

4 Directive 2002/46/EC of the European Parliament and of the Council of 10 June 2002 on the approximation of the laws of the Member States relating to food supplements. Official Journal of the European Union: L136/85, 12 July 2002.

5 Common Position (EC) No. 3/2006 adopted by the Council on 8 December 2005 with a view to adopting Regulation (EC) No. .../2006 of the European Parliament and of the Council of ...on nutrition and health claims made on foods (2006/C $80 \mathrm{E} / 03)$. Official Journal of the European Union: C80E/43 April 2006.
6 Common Position (EC) No. 2/2006 adopted by the Council on 8 December 2005 with a view to adopting Regulation (EC) No .../2006 of the European Parliament and of the Council of ... on the addition of vitamins and minerals and of certain other substances to foods (2006/C 80 E/02). Official Journal of the European Union: C80E/27, 4 April 2006.

7 Directive 2001/83/EC of the European Parliament and of the Council of 6 November 2001 on the Community code relating to medicinal products for human use. Official Journal of the European Union: L311/67, 28 November 2001.

8 Directive 2004/27/EC of the European Parliament and of the Council of 31 March 2004 amending Directive 2001/83/EC on the Community code relating to medicinal products for human use. Official Journal of the European Union: L136/34, 30 April 2004.

9 Case 227/82. Judgment of the Court (Fifth Chamber) of 30 November 1983. Criminal proceedings against Leendert van Bennekom. European Court Reports 1983, p 3883.

10 Case C-369/88. Judgment of the Court (Fifth Chamber) of 21 March 1991. Criminal proceedings against Jean-Marie Delattre. European Court Reports 1991, p I-1487.

11 Case C-60/89. Judgment of the Court (Fifth Chamber) of 21 March 1991. Criminal proceedings against Jean Monteil and Daniel Samanni. European Court Reports 1991, p I-1547.
12 Case C-112/89. Judgment of the Court (Fifth Chamber) of 16 April 1991. Upjohn Company and Upjohn NV v Farzoo Inc. and J. Kortmann. European Court Reports 1991, p I1703.

13 Case C-290/90. Judgment of the Court of 20 May 1992. Commission of the European Communities v Federal Republic of Germany. European Court Reports 1992, p I-3317.

14 Case C-219/91. Judgment of the Court (Fifth Chamber) of 28 October 1992. Criminal proceedings against Johannes Stephanus Wilhelmus Ter Voort. European Court Reports 1992, p I-5485.

15 Joined Cases C-211/03, C-299/03 and C$316 / 03$ to C-318/03. Judgment of the Court (First Chamber) of 9 June 2005. References for a preliminary ruling from the Oberverwaltungsgericht für das Land NordrheinWestfalen: HLH Warenvertriebs GmbH, Orthica BC v Federal Republic of Germany, European Court Reports 2005, p I-5141.

16 Bogaert P: EC Pharmaceutical Law. Chancery Law Publications 1992. ISBN 0-47193648-0.

-17 Bast A, Chandler F, Choy PC, Delmulle LM, Gruenwals J, Halkes BA, Keller K, Koeman JH, Peters P, Przyrembel H, de Ree EM, Renwick AG, Vermeer ITM: Botanical health products: positioning and requirements for effective and safe use. Environ Toxicol Pharmacol 2002;12:195-211. 
18 Council of Europe: Guidelines on the quality, safety and marketing of plan-based food supplements. 2005;http://www.coe.int/t/e/ social_cohesion/soc\%2Dsp/public_health/ nutrition_food_consumer_health/Guidelin es $\% 20$ food $\% 20$ supplements $\% 20 \% 2023.06 .0$ 5.pdf ref

19 European Food Safety Authority: Discussion Paper on Botanicals and Botanical Preparations Widely Used as Food Supplements and Related Products: Coherent and Comprehensive Risk Assessment and Consumer Information Approaches. 2004:http:// www.efsa.eu.int/science/sc_commitee/sc documents/616/scdoc_advice03_botanicals_en1.pdf

20 Regulation (EC) No 258/97 of the European Parliament and of the Council of 27 January 1997 Concerning Novel Foods and Novel Food Ingredients. Official Journal of the European Union: L043/1, 14 February 1997.

21 Scientific Committee for Food: Opinions of the Scientific Committee for Food on the Assessment of Novel Foods. Reports of the Scientific Committee for Food, 40th Series, 1997, http://europa.eu.int/comm/food/fs/sc/ scf/reports/scf_reports_40.pdf

-22 Schilter B, Andersson C, Anton R, Constable A, Kleiner J, O'Brien J, Renwick AG, Korver O, Smit F, Walker R: Guidance for the safety assessment of botanicals and botanical preparations for use in food and food supplements. Food Chem Toxicol 2003;41:16251649.

23 AFSSA Démarche d'évaluation de la sécurité, de l'intérêt et de l'allégation des denrées alimentaires contenant des plantes destinées a la consommation humaine. 2003; http:// www.afssa.fr/ftp/afssa/actu/RapportPlantes.pdf

24 US Food and Drug Administration. http:// www.fda.gov/

25 World Health Organisation. http://www. who.int/medicines/publications/pharmprep/en/

26 US Agency for Healthcare Research and Quality. http://www.ahrq.gov/

27 US Pharmacopoeia. http://www.uspnf.com/ uspnf $/ \operatorname{login}$

28 US Pharmacopoeia Dietary Supplement Verification Program. http://www.usp.org/ USPVerified/

29 American Herbal Pharmacopoeia. http:// www.herbal-ahp.org/bot_ref.htm

30 American Herbal Products Association. http://www.ahpa.org/
31 American College of Clinical Pharmacy, Natural Medicines Comprehensive Database. http://www.accp.com/th_06nmcd.php

32 Bundesinstituts für Arzneimittel und $\mathrm{Me}$ dizinprodukte, Kommission E. http://www. bfarm.de/cln_042/nn_424630/DE/Arzneimittel/besTherap/amPflanz/ampflanz-node. html_nnn = true\#doc424646bodyText2

33 Health Canada National Health Products Directorate. http://www.hc-sc.gc.ca/sr-sr/finance/nhprp-prpsn/index_e.html

34 European Cooperative on Phytotherapy http://www.escop.com/

35 European Pharmacopeia Commission. http://www.pheur.org/site/page_607.php

36 British Herbal Medicine Association. http:// www.bhma.info/

37 Physician's Desk Reference. http://www.pdr. net/Home/Home.aspx

38 EMEA Committee for Medicinal Products for Human use (CHMP) - Committee for Medicinal Products for Veterinary Use (CVMP): Guideline on Quality of Herbal Medicinal Products / Traditional Herbal Medicinal Products. CPMP/QWP/2819/00 Rev 1 - EMEA/CVMP/814/00 Rev 1. 30 March 2006. www.emea.eu.int/pdfs/human/qwp/281900en.pdf

39 EMEA Committee for Medicinal Products for Human use (CHMP) - Committee for Medicinal Products for Veterinary Use (CVMP): Guideline on Specifications: Test Procedures and Acceptance Criteria for Herbal Substances, Herbal Preparations and Herbal Medicinal Products / Traditional Herbal Medicinal Products. CPMP/QWP/ 2820/00 Rev 1 - EMEA/CVMP/815/00 Rev 1. 30 March 2006. www.emea.eu.int/pdfs/ human/qwp/282000en.pdf

40 World Health Organization: WHO Expert Committee on Specifications for Pharmaceutical Preparations. http://www.who.int/ medicines/publications/pharmprep/en/; Good manufacturing practices: supplementary guidelines for the manufacture of herbal medicinal products. World Health Organ Tech Rep Ser 1996;863: 34th Report, pp 109113, 1996 (Annex 8). http://whqlibdoc.who. int/trs/WHO_TRS_863_(p99-p194).pdf; WHO Guidelines on Good Agricultural and Collection Practices (GACP) for Medicinal Plants. Geneva, WHO, 2003. whqlibdoc. who.int/publications/2003/9241546271.pdf; Quality Control Methods for Medicinal Plant Materials, 1998, ISBN 924154510 0.whqlibdoc.who.int/publications/1998/ 9241545100.pdf
41 European Commission: Rapid Alert System for FoodandFood(RASFF).http://ec.europa. eu/food/food/rapidalert/index_en.htm

42 International Life Sciences Institute: Passclaim Project. http://passclaim.ilsi.org/file/ Passclaim\%20Newsflash\%20final\%20result s\%208de05.pdf

-43 Aggett PJ, Antoine JM, Asp NG, Bellisle F, Contor L, Cummings JH, Howlett J, Muller DJ, Persin C, Pijls LT, Rechkemmer G, Tuijtelaars S, Verhagen H: PASSCLAIM: consensus on criteria. Eur J Nutr 2005;44(suppl 1): i5-i30.

44 Richardson DP: The scientific substantiation of health claims with particular reference to the grading of evidence Eur J Nutr 2005;44(suppl 1):319-324.

45 EMEA Working Party on Herbal Medicinal Products: Updated draft points to consider on the evidence for safety and efficacy required for well-established herbal medicinal products in bibliographic applications. 25 October 1999. EMEA/HMPWP/23/99. www. emea.eu.int/pdfs/human/hmpc/002399en. pdf

46 EMEA Working Party on Herbal Medicinal Products: Final concept paper on the implementation of different levels of scientific evidence in core-data for herbal drugs. 3 March 2004. EMEA/CPMP/HMPWP/1156/03. www.emea.eu.int/pdfs/human/h mpc/ 115603en.pdf

47 World Cancer Research Fund - American Institute for Cancer Research: Food, Nutrition and the Prevention of Cancer: A Global Perspective. Washington, World Cancer Research Fund, 1997. http://www.wcrf-uk.org/ report/index.lasso

48 US Food and Drug Administration, Center for Food Safety and Applied Nutrition: Guidance for Industry: Significant Scientific Agreement in the Review of Health Claims for Conventional Foods and Dietary Supplements. 22 December 1999. www.cfsan.fda. gov/ dms/ssaguide.html

49 WHO Monographs on Selected Medicinal Plants, vol I, 1999, ISBN 924 154517; vol II, 2002, ISBN 924 154537. whqlibdoc.who.int/ publications/1999/9241545178.pdf

50 Agence Française de Sécurité Sanitaire des Aliments; http://www.afssa.fr/ 